УДК 338.27

DOI: $10.14451 / 1.179 .102$

\title{
ПРИМЕНЕНИЕ ТРЕНД-СЕЗОННЫХ МОДЕЛЕЙ ПРИ ПРОГНОЗИРОВАНИИ ПАССАЖИРСКИХ ЖЕЛЕЗНОДОРОЖНЫХ ПЕРЕВОЗОК
}

\author{
(c) 2019 Проскурякова Елена Александровна \\ кандидат экономических наук, доцент, кафедра «Экономика транспорта» \\ Петербургский государственный университет путей сообщения Императора Александра I, \\ Россия, Санкт-Петербург
}

Статья посвящена вопросам прогнозирования пассажирских перевозок на железнодорожном транспорте. Рассмотрена специфика пассажирских перевозок, которую необходимо учитывать при их прогнозировании. Разработан прогноз пассажирских перевозок на основе тренд-сезонной модели. Даны рекомендации по использованию полученных результатов прогноза.

Ключевые слова: социально-экономическое прогнозирование, методы прогнозирования, тренд, сезонные колебания, экстраполяция, пассажирские перевозки, железнодорожный транспорт, пассажирский комплекс железнодорожного транспорта.

Пассажирские перевозки занимают особое место на транспортном рынке Российской Федерации (РФ). Это связано прежде всего с их ролью в экономике страны, социальной составляющей и государственным регулированием [5].

Уровень развития пассажирского транспорта оказывает влияние на многие сферы жизни общества. При этом важная особенность пассажирских перевозок заключается в том, что спрос населения на транспортные услуги представляет собой вторичную потребность, которая непосредственно связана с удовлетворением других потребностей. Объемы и направления пассажирских перевозок зависят от множества факторов: экономических, политических, социальных, демографических, культурных, экологических, технических. Важной спецификой пассажирских перевозок является их ярко выраженная временная неравномерность, определяемая периодами отпусков, школьных и студенческих каникул, праздничных дней, сезонным характером работы многих предприятий. Эти особенности необходимо учитывать при прогнозировании пассажирских железнодорожных перевозок.

Проблема прогнозирования пассажирских железнодорожных перевозок является одной из актуальных проблем экономики транспорта. Основными исследуемыми показателями являются: объемы пассажирских перевозок (пассажиры, пасс.) и пассажирооборот (пассажирокилометры, пасс.-км.). Результаты прогнозов используются при принятии управленческих решений на разных уровнях, от которых в конечном счете зависит эффективность функци- онирования пассажирского комплекса железнодорожного транспорта.

Для прогнозирования пассажирских перевозок на железнодорожном транспорте преимущественно используются следующие методы: экспертные, экстраполяция и экономико-математическое моделирование [4]. Наиболее распространенной является экстраполяция временных рядов, представляющая собой продление в будущее тенденций, установленных на прошлом периоде времени.

Применение методов прогнозной экстраполяции на практике связано со следующими ограничениями [1]:

- фактические значения прогнозируемого показателя на протяжении всего исследуемого периода должны иметь устойчивую тенденцию к возрастанию или убыванию;

- в прогнозируемом периоде не ожидается существенного изменения факторов, оказывающих влияние на изучаемый показатель.

Разработаем прогноз пассажирских железнодорожных перевозок методом экстраполяции тренда с учетом сезонной составляющей. Для этого используем данные об объемах пассажирских железнодорожных перевозок дальнего следования в регионе $\mathrm{N}$ (таблица 1).

Для объемов пассажирских железнодорожных перевозок дальнего следования характерно наличие сезонных колебаний, что наглядно представлено на рисунке 1 .

Разработка прогноза на основе тренд-сезонной модели состоит из ряда последовательных этапов. Рассмотрим подробнее каждый из них. 
Таблица 1. Объем перевозок пассажиров, тыс. пасс.

\begin{tabular}{|c|c|c|c|}
\hline Месяц & 2016 & 2017 & 2018 \\
\hline 1 & 1287,0 & 1397,8 & 1429,9 \\
\hline 2 & 989,1 & 1040,9 & 1099,0 \\
\hline 3 & 1119,6 & 1154,5 & 1120,6 \\
\hline 4 & 1176,4 & 1198,1 & 1129,3 \\
\hline 5 & 1434,4 & 1460,3 & 1520,5 \\
\hline 6 & 1782,8 & 1859,1 & 1980,9 \\
\hline 7 & 2048,8 & 2147,3 & 2276,7 \\
\hline 8 & 1943,2 & 2050,0 & 2159,5 \\
\hline 9 & 1302,1 & 1308,7 & 1406,3 \\
\hline 10 & 1280,9 & 1263,3 & 1319,4 \\
\hline 11 & 1288,1 & 1306,0 & 1326,7 \\
\hline 12 & 1302,7 & 1362,2 & 1447,7 \\
\hline Итого & 16955,2 & 17548,1 & 18216,6 \\
\hline
\end{tabular}

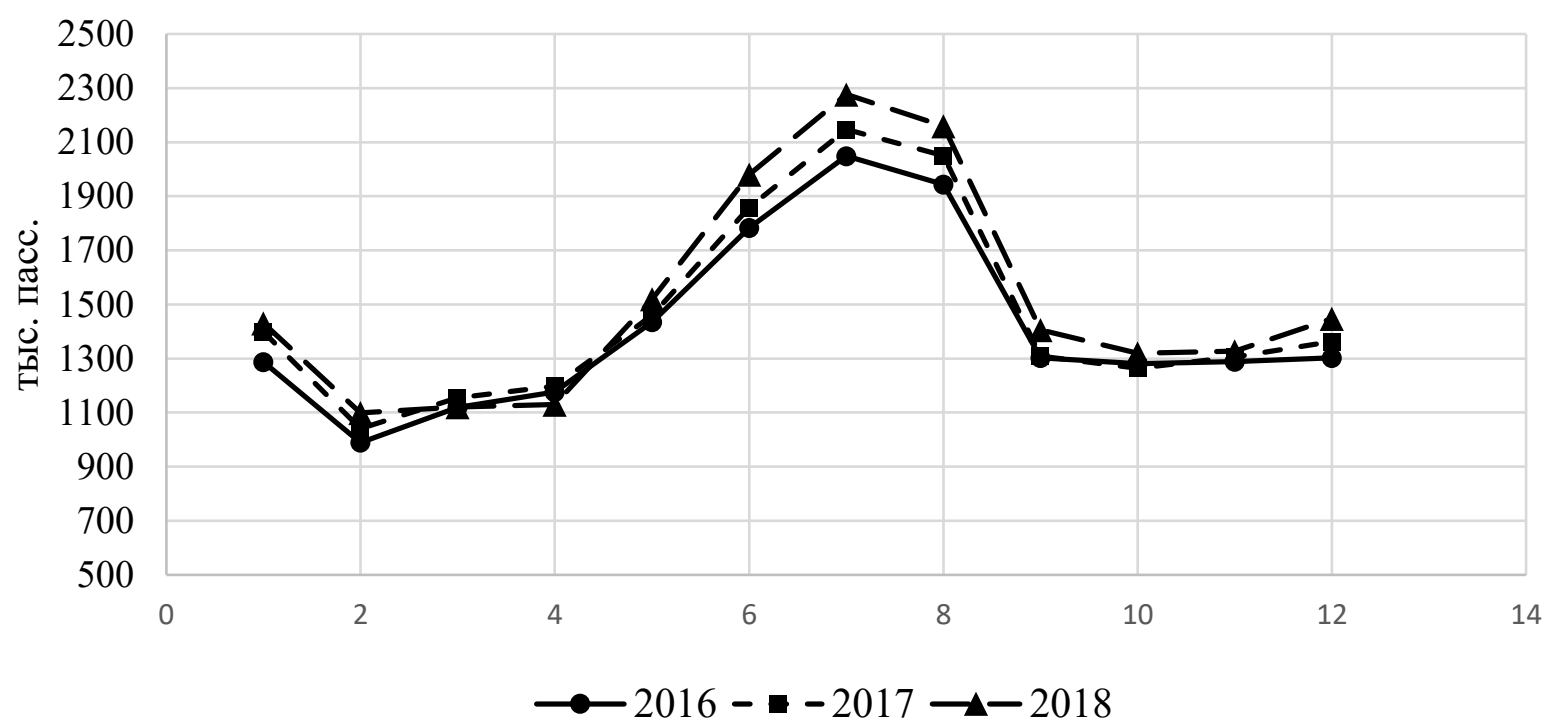

Puc. 1. Сезонные колебания пассажирских железнодорожных перевозок дальнего следования

Этап 1. Аналитическое выравнивание временного ряда - выделение тренда.

Тренд - аналитическое или графическое представление основной тенденции изменения объемов пассажирских перевозок во времени. Произведем выравнивание временного ряда по уравнению прямой $(\mathrm{y}=\mathrm{a}+\mathrm{bt})$, параболы $\left(\mathrm{y}=\mathrm{a}+\mathrm{bt}+\mathrm{ct}^{2}\right), \quad$ кубической параболы $\left(\mathrm{y}=\mathrm{a}+\mathrm{bt}+\mathrm{ct}^{2}+\mathrm{dt}^{3}\right)$ и степенной функции $(\mathrm{y}=\mathrm{at})$. Параметры функций были найдены методом наименьших квадратов:

прямая: $\mathrm{y}=6,3432 \mathrm{t}+1347,1$;

парабола: $\mathrm{y}=-0,1806 \mathrm{t}^{2}+13,026 \mathrm{t}+1304,8$;

кубическая парабола: $\mathrm{y}=0,0337 \mathrm{t}^{3}-2,0486 \mathrm{t}^{2}$

$+41,052 \mathrm{t}+1212,5$;

степенная функция: $\mathrm{y}=1209,7 \mathrm{t}^{0}, 0619$.
Результаты выравнивания исходного временного ряда представлены на рисунке 2. Графический метод дает возможность получить визуальную оценку изучаемого процесса и обосновать выбор вида функциональной зависимости. От того, насколько удачно будет сделан выбор вида функциональной зависимости, зависят последующие результаты прогноза.

Эman 2. Определение наилучшей формы тренда.

Существуют различные методы определения наилучшей формы тренда [2]. В рамках данной работы используется критериальный метод. В качестве статистического критерия выступает среднее квадратическое отклонение $(\sigma)$ : 


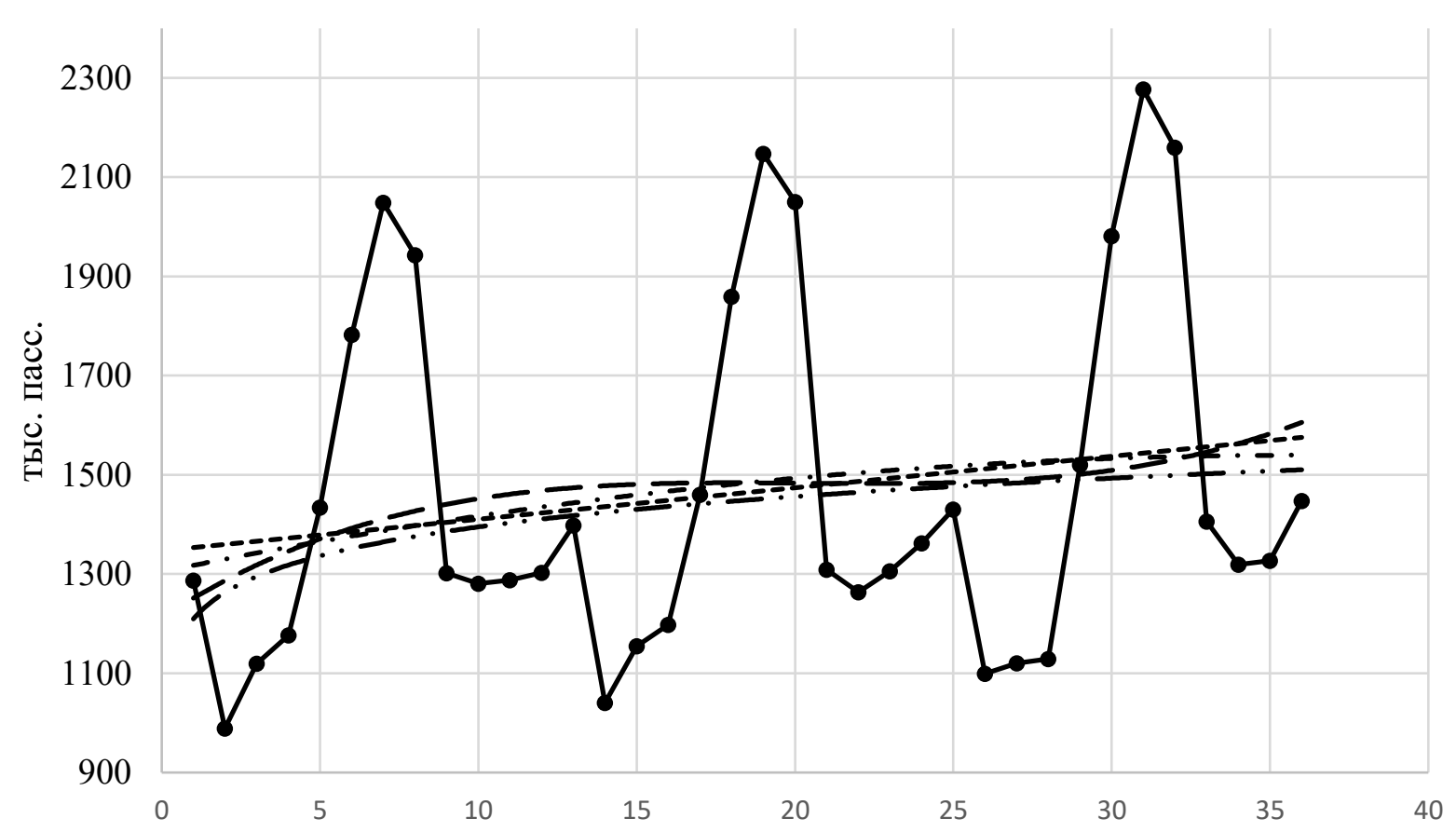

- - факт ----・прямая $-\cdot \cdot$ парабола - - кубическая парабола $-\cdots$ степенная

Puc. 2. Аналитическое выравнивание временного ряда

$\sigma=\sqrt{\frac{\left(\mathrm{y}_{\mathrm{i}}-\hat{\mathrm{y}}_{\mathrm{i}}\right)^{2}}{\mathrm{n}}}$

где $\mathrm{y}_{\mathrm{i}}$ - фактические значения объемов пассажирских перевозок;

$\hat{\mathrm{y}}_{\mathrm{i}}-$ расчетные значения;

$\mathrm{n}$ - количество значений.

Результаты расчетов среднего квадратического отклонения для каждого вида функциональной зависимости представлены в таблице 2.

Минимальное значение среднее квадратическое отклонение принимает у кубической параболы, следовательно, эта функция наиболее точно описывает исходные статистические данные.

Эman 3. Экстраполяция тренда.

При экстраполяции тренда рекомендуется, чтобы период времени, на который разрабатывается прогноз, не превышал третьей части длины базы прогнозирования. В нашем примере анализируются статистические данные за три года, следовательно, прогноз разрабатыва- ется сроком на один год. Полученный методом экстраполяции кубической параболы точечный прогноз представлен на рисунке 3 (продолжение тренда с 37 по 48 месяца).

Эman 4. Расчет индексов сезонности.

Для учета сезонных колебаний при прогнозировании необходимо рассчитать индивидуальные и средние индексы сезонности:

$$
\begin{aligned}
& \mathrm{i}_{\text {сезi, } \mathrm{t}}=\frac{\mathrm{y}_{\mathrm{i}}}{\hat{\mathrm{y}}_{\mathrm{i}}} \\
& I_{\text {сез } \mathrm{i}}=\frac{\sum_{\mathrm{t}=1}^{\mathrm{n}} \mathrm{i}_{\text {сез } \mathrm{i}, \mathrm{t}}}{\mathrm{n}}
\end{aligned}
$$

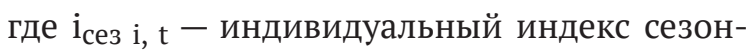
ности і-го месяца в $\mathrm{t}-\mathrm{м}$ году;

$\mathrm{I}_{\text {сез і }}-$ средний индекс сезонности і-го месяца;

Индивидуальные индексы сезонности характеризуют сезонность в границах конкретно-

Таблица 2. Значения среднего квадратического отклонения, тыс. пасс.

\begin{tabular}{|c|c|c|c|c|}
\hline Вид функции & Прямая & Парабола & $\begin{array}{c}\text { Кубическая } \\
\text { парабола }\end{array}$ & Степенная \\
\hline б, тыс. пасс. & 346,84 & 346,41 & 345,15 & 346,52 \\
\hline
\end{tabular}


го года. Средние (общие) индексы сезонности характеризуют устойчивую тенденцию сезонности для нескольких лет; представляют собой среднее значение из индивидуальных индексов сезонности за n лет. Для расчет средних индексов сезонности рекомендуется использовать статистические данные не менее, чем за три года.

Результаты расчетов индивидуальных и средних индексов сезонности для каждого месяца представлены в таблице 3.

На основе полученных расчетов можно сделать следующие выводы:

- диапазон изменений коэффициентов месячной неравномерности объемов пассажирских перевозок дальнего следования составляет $0,71-1,47$

- максимальное значение объемов пассажирских перевозок дальнего следования приходится на август, средний индекс сезонности принимает значение 1,47 ;

- минимальное значение объемов пассажирских перевозок дальнего следования приходится на февраль, средний индекс сезонности принимает значение 0,71 ;

- в течение рассматриваемого периода масштаб вариабельности коэффициентов месячной неравномерности имеет тенденцию к увеличению: 2016 - 0,75; 2017 - 0,76; 2018 - 0,78.

Этап 5. Моделирование исходного временного ряда и прогноз с учетом сезонной составляющей.

На этом этапе рассчитанные по уравнению кубической параболы уровни ряда умножим на соответствующие для каждого месяца значения средних индексов сезонности:

$$
\hat{\mathrm{y}}_{\mathrm{i}}^{*}=\hat{\mathrm{y}}_{\mathrm{i}} \cdot \mathrm{I}_{\text {сезi }}
$$

Выровненные значения и прогноз объемов пассажирских перевозок дальнего следования по уравнению кубической параболы с учетом сезонных колебаний представлен на рисунке 3 (тренд-сезонная модель).

Эman 6. Расчет доверительного интервала прогноза.

Точное совпадение фактических данных и прогностических точечных оценок, полученных методом экстраполяции тренда, имеет малую вероятность. Поэтому целесообразно определить доверительный интервал прогноза - интервал, в который с определенным уровнем вероятности может попасть фактическое значение прогнозируемого показателя. Доверительный интервал прогноза определяется по формуле:

$$
\hat{\mathrm{y}}_{\mathrm{i}}-\mathrm{t}_{\alpha} \sigma \leq \hat{\mathrm{y}}_{\mathrm{i}} * \leq \hat{\mathrm{y}}_{\mathrm{i}}+\mathrm{t}_{\alpha} \sigma
$$

где $\mathrm{t} \alpha$ - табличное значение $\mathrm{t}$-статистики Стьюдента с заданным уровнем вероятности Р.

Для расчетов примем степень вероятности попасть в доверительный интервал $\mathrm{P}=0,95-$ «почти наверняка». Интервальный прогноз объемов пассажирских перевозок дальнего следования представлен на рисунке 3 (доверительный интервал) и в таблице 4.

Таким образом, на основе анализа статистических данных был получен прогноз объемов пассажирских перевозок дальнего следо-

Таблица 3. Коэффициенты месячной неравномерности объемов перевозок

\begin{tabular}{|c|c|c|c|c|c|c|c|c|c|c|c|c|c|}
\hline \multirow{2}{*}{ Год } & \multicolumn{12}{|c|}{ Месяцы года } & \multirow{2}{*}{ 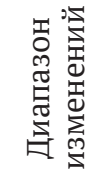 } \\
\hline & 1 & 2 & 3 & 4 & 5 & 6 & 7 & 8 & 9 & 10 & 11 & 12 & \\
\hline 2016 & 0,91 & 0,70 & 0,79 & 0,83 & 1,02 & 1,26 & 1,45 & 1,38 & 0,92 & 0,91 & 0,91 & 0,92 & $\begin{array}{c}0,70- \\
1,45\end{array}$ \\
\hline 2017 & 0,96 & 0,71 & 0,79 & 0,82 & 1,00 & 1,27 & 1,47 & 1,40 & 0,89 & 0,86 & 0,89 & 0,93 & $\begin{array}{c}0,71- \\
1,47\end{array}$ \\
\hline 2018 & 0,94 & 0,72 & 0,74 & 0,74 & 1,00 & 1,30 & 1,50 & 1,42 & 0,93 & 0,87 & 0,87 & 0,95 & $\begin{array}{c}0,72- \\
1,50 \\
\end{array}$ \\
\hline 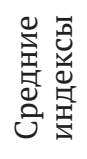 & 0,94 & 0,71 & 0,77 & 0,80 & 1,01 & 1,28 & 1,47 & 1,40 & 0,91 & 0,88 & 0,89 & 0,94 & $\begin{array}{c}0,71- \\
1,47\end{array}$ \\
\hline
\end{tabular}
пассажиров дальнего следования 


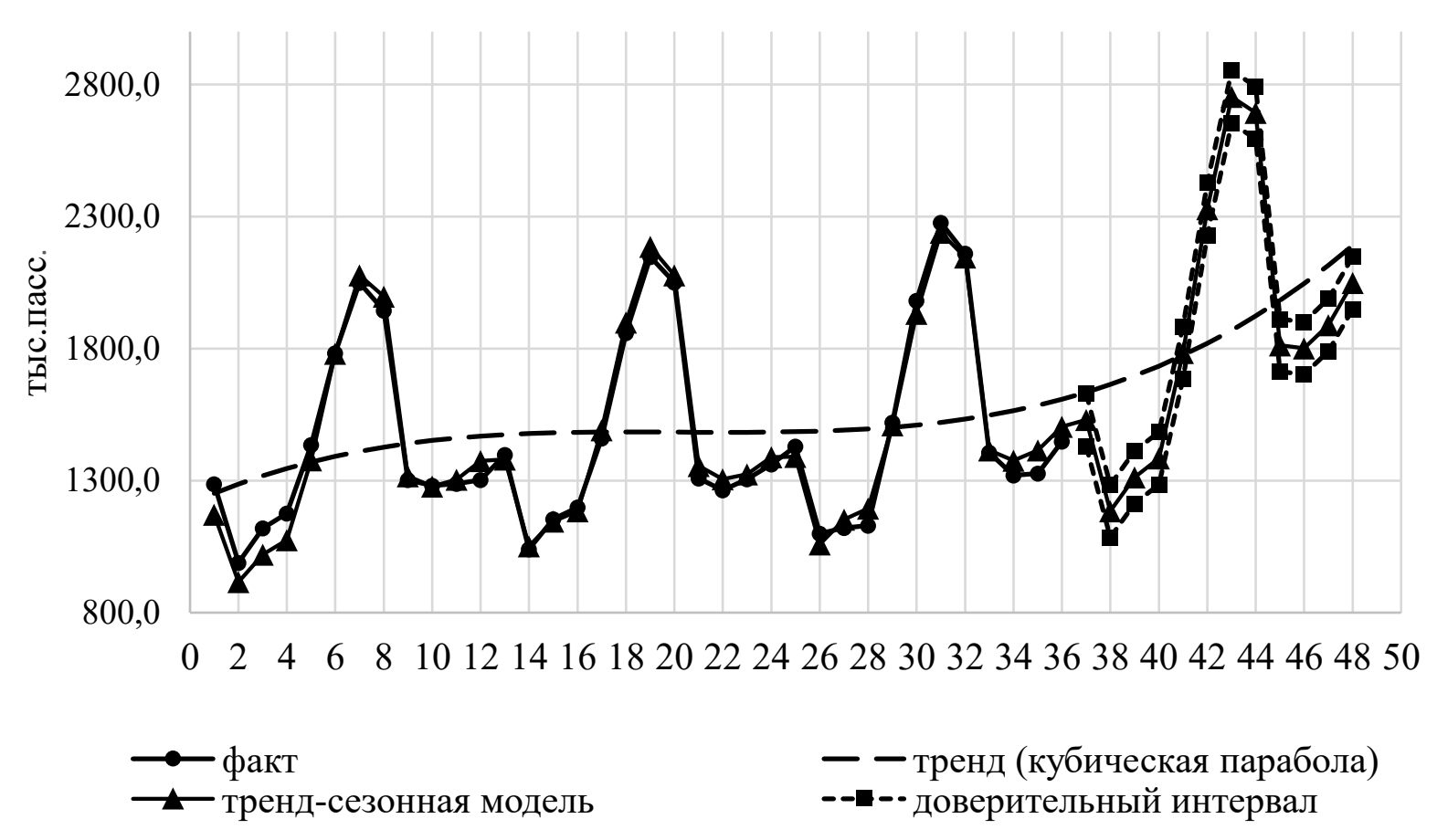

Puc. 3. Моделирование временного ряда и прогноз объемов пассажирских перевозок дальнего следования на основе тренд-сезонной модели

Таблица 4. Прогнозные значения объемов пассажирских перевозок дальнего следования на 2019 год, тыс. пасс.

\begin{tabular}{|c|c|c|c|}
\hline Месяц года & Точечный прогноз & $\begin{array}{c}\text { Нижняя граница } \\
\text { доверительного интервала }\end{array}$ & $\begin{array}{c}\text { Верхняя граница } \\
\text { доверительного интервала }\end{array}$ \\
\hline 1 & 1529,7 & 1430,3 & 1629,1 \\
\hline 2 & 1184,3 & 1084,9 & 1283,7 \\
\hline 3 & 1312,2 & 1212,7 & 1483,9 \\
\hline 4 & 1384,5 & 1285,1 & 1883,1 \\
\hline 5 & 1783,7 & 1684,3 & 2427,4 \\
\hline 6 & 2328,0 & 2228,6 & 2852,3 \\
\hline 7 & 2752,9 & 2653,5 & 1911,9 \\
\hline 8 & 2692,5 & 2593,1 & 1899,9 \\
\hline 9 & 1812,4 & 1713,0 & 1988,3 \\
\hline 10 & 1800,5 & 1701,0 & 2148,6 \\
\hline 11 & 1888,8 & 1789,4 & 194,0 \\
\hline 12 & 2049,2 & 1949,8 & \\
\hline
\end{tabular}

вания с применением тренд-сезонной модели. В современных условиях вследствие быстрых и трудно предсказуемых изменений внешней среды для повышения точности прогнозов экстраполяционные методы целесообразно дополнять другими методами прогнозирования. Так, при прогнозировании пассажирских перевозок целесообразно учитывать следующую информацию: развитие экономики различных регионов; уровень доходов, плотность, подвижность и культурный уровень населения; уровень развития городов и курортов; техническая вооруженность транспорта; сооружение новых и реконструкция существующих железнодорожных линий; уровень развития других видов транспорта. Важны также соотношение тарифов, продолжительность поездки и перечень услуг, предоставляемых железнодорожным транспор- 
том и его основными конкурентами: воздушным и автомобильным видами транспорта [3].

Результаты прогнозов объемов пассажирских железнодорожных перевозок рекомендуется использовать при определении потребностей в подвижном составе, трудовых ресурсах, топливе, материалах; в ремонте и развитии посто- янных устройств, обеспечивающих перевозки пассажиров [6]. От качества разрабатываемых прогнозов зависят себестоимость, расходы и доходы от пассажирских перевозок и, следовательно, экономическая эффективность деятельности пассажирского комплекса железнодорожного транспорта.

\section{Библиографический список}

1. Дуброва Т.А. Прогнозирование социально-экономических процессов. Статистические методы и модели: учебное пособие.- М.: Маркет ДС, 2007.-192 с.

2. Дуброва Т.А. Статистические методы прогнозирования: учебное пособие для вузов.- М.: ЮНИТИ-ДАНА, 2003.- 206 c.

3. Железнодорожные пассажирские перевозки: Монография / под. ред. Г.В. Верховых.- СПб.: СевероЗападный региональный центр «РУСИЧ», «Паллада-медиа», 2012. - 520 с.

4. Проскурякова Е.А., Яхно А.Д. Социально-экономическое прогнозирование: учебное пособие - СПб.: ПГУПС, 2009.- 92 c.

5. Рынок пригородных железнодорожных перевозок: управление и экономика: Монография / М.А. Шнейдер, Е.А. Проскурякова.-СПб.: НП-Принт, 2012.- 288 с.

6. Экономика пассажирского транспорта: учебное пособие / под общей ред. проф. В.А. Персианова. М.: КНОPУC, 2012-400 c. 